\title{
Making wonders with burned fingers: The experiences of ELT teachers during the online education process
}

\author{
Pınar Şahin-Durmaz ${ }^{a *}$ (D), Naciye Kunt ${ }^{b}$ (D) \\ ${ }^{a}$ Middle East Technical University Northern Cyprus Campus, Northern Cyprus \\ ${ }^{\mathrm{b}}$ Eastern Mediterrenean University, Northern Cyprus
}

Suggested citation: Şahin Durmaz, P. \& Kunt, N. (2022). Making wonders with burned fingers: The experiences of ELT teachers during the online education process. Journal of Educational Technology \& Online Learning, 5(1), 144-168.

\begin{tabular}{l} 
Article Info \\
\hline Keywords: \\
Teacher well-being \\
Online education \\
Auto-photography \\
Covid-19 pandemic \\
Adaptation to the new normal
\end{tabular}

Research Article

\begin{abstract}
The Covid-19 pandemic has caused a rapid shift in education all around the world, including Northern Cyprus. Although the related literature focused on the general perceptions of teachers and their experiences or challenges during the online education process that started early in 2020, there seems to be a gap in the literature regarding the well-being of the English language teachers from a broader perspective taking their interwoven roles and identities into consideration. In an attempt to fill this void in the literature, this study investigated the experiences of seven English language teachers during the online education period English medium university in Northern Cyprus regarding (1)work-life balance, (2) professional development, (3) academic activities and research, (4) collaboration and communication among colleagues, (5) relationship with the administration, and (6) teaching English online. The necessary data were collected via a demographic survey along with an auto-photography task, in which the participants took photos for the themes and explained them in short abstracts, and focus group interviews were conducted. The findings revealed that although the teachers had certain financial, psychological, and teaching-related challenges in this process, they adapted to the new normal by making sacrifices, learning from their mistakes. That is to say, adaptation to online teaching took some time, energy, practice, and collaboration, but eventually, teachers managed to survive and even enjoy the whole process despite the pain they had in their fingers.
\end{abstract}

\section{Introduction}

The Covid-19 pandemic has led to a sudden transformation in many sectors including education around the world. In order to prevent the spread of the disease, all the countries around the world adopted the policy of closing the schools and moving all the educational practices to online platforms. While some of the universities have offered synchronous lessons, others preferred to continue their educational activities in asynchronous classes where instructors provide the learners with recorded lessons and related materials to be utilized in the students' own time and pace (Crawford et al., 2020; Hodges et al., 2020). Since the interaction between or among the students and instructors in online education is mediated by technology, the design of the learning environment and the online tools to be used in the education process have been of utmost importance for the stakeholders in higher institutions.

With the confirmation of the first Covid-19 cases in Northern Cyprus on 10 March 2020, all schools, public and private, at all levels were closed as a precaution against the coronavirus until 15 March 2020. This was

\footnotetext{
* Corresponding author. Middle East Technical University Northern Cyprus Campus, Northern Cyprus. e-mail addresses: pinar.sahin2015@gmail.com, naciye.kunt@emu.edu.tr
} 
later extended to the whole semester and the next academic year considering the safety of the students and the staff under the conditions of the fast spread of the pandemic. Upon the closure of the universities, most of the students gradually returned to their hometowns. Meanwhile, teachers have both faced many challenges regarding the use of online tools, teaching online, making the assessments on online platforms and communicating with colleagues effectively and had to deal with their well-being under the conditions of lock-down. When the schools were closed and the decision for online education was made, teachers started to explore all forms of available online educational or conference platforms, tools and applications to provide the learners with a class-like, interactive environment in an online platform. In addition to the Moodle platform of the universities, online tools such as Zoom, Webex and Whatsapp were utilized both by the students and among the teachers to enable a practical communication.

Considering that technology was formerly used mainly as a supplement to in-class teaching rather than the main channel of instruction, the process of adaptation to online teaching was both productive and stressful for the teachers. Although they had a chance to learn more about online resources to facilitate learning or teaching and increase their media literacy (Oyedotun, 2020), that process was challenging for them as they were professionally and personally unprepared for a fully online teaching experience (Gao and Zhang 2020). The collapse of work-life balance in this period among teachers has been one of the chief topics mentioned by many scholars around the world. Maintaining the work-life balance has been especially difficult for the parent teachers as they have to be a parent, teacher and professional, all at the same time during the day (Clark et al., 2020). This struggle to balance parenthood and the expectations of the schools or institutions from the teachers has also been defined as the mental load parent-teachers have to carry (NYU Langone Health, 2021).

Recently, many researchers have examined the experiences of teachers from different contexts regarding the challenges and opportunities brought by the emergency online education process. However, there seems to be very few studies that investigate how teachers deal with their personal realities like juggling work and home at the same time, extra teaching-related responsibilities such as being a teacher-leader or in-service teacher trainer in this period or if/how they can keep their work-life balance and how these efforts have affected their well-being, the communication with others and their teaching (and learning) practices from a broader perspective. Moreover, it seems that no studies, to the knowledge of the researcher, have focused on the experiences of ELT teachers in the online education period regarding their engagement in professional development activities and academic research studies. Considering that the ones existing rely on purely verbal or written accounts, this study aims to contribute to this growing area of research by adopting a relatively new approach in qualitative research: visual methodology. It is hoped that the inclusion of multimodality in the present study will contribute to a deeper and more comprehensive understanding of the experiences, challenges and opportunities of the English language teachers teaching in a Northern Cyprus context during the Covid-19 period. In line with this aim, the following research question and sub themes were formulated to guide the study:

What are the views and experiences of English language teachers during the Covid-19 online education process in terms of:
a) Work-life balance
b) Professional development
c) Academic activities and research during online period
d) Communication and collaboration among colleagues
e) Relationship with or support from administration
f) Online teaching and the use of online tools 


\section{Literature Review}

Since the beginning of the online education process during the pandemic period, many scholars have discussed the possible opportunities and challenges of remote education both from the students' and the teachers' perspective. According to Oyedotun (2020), for example, online education has brought about some benefits such as thrived use of online resources, increased media literacy, the development of blended learning, and enhanced engagement outside the confines of a traditional university classroom. Similarly Vyas and Butakhieo (2020) mentioned the beneficial effects of working from home during the pandemic period on both employers and employees. They state that working from home has been quite advantageous in terms of reduced commuting time, avoiding office politics, using less office space, increased motivation, higher talent retention, job satisfaction, and better productivity (Vyas \& Butakhieo, 2020). Conversely, it has been reported that the sudden shift to remote learning caught the universities and the staff off guard as most schools were ill-prepared for such a long and unexpected process. Lack of digital resources (including a practical training or digital tools such as laptops and cameras), reduced student-teacher engagement, slow and extended work due to the remote communication problems, testing-related practices, cybersecurity problems, mental health challenges among teachers and students, and domestic affairs have been mentioned as some of the problems teachers have faced during this period (Oyedotun, 2020). In addition to the teaching-related challenges, the teachers have also had certain difficulties such as trying to manage the blurred line between work and family, distractions, social isolation due to working from home and lock-down policies in the countries (Vyas \& Butakhieo, 2020).

Although the literature regarding the experiences of teachers during the COVID-19 period is scant, it can be said that the pandemic period and the new-normal in the educational arena has put a tremendous load on the shoulders of the teachers, alarming high levels of teacher stress and burnout (Sokal et al., 2021). Having looked at the Canadian teachers' attitudes toward change, efficacy, and burnout during the COVID-19 pandemic, Sokal et al. (2020) stated that although increased efficacy for classroom management and increased sense of accomplishment have been observed among the teachers, they also demonstrated increasing exhaustion and cynicism over the first three months of the pandemic as teachers were not convinced enough about the merits of remote teaching. Similar results were reported by Vu et al. (2020) who investigated Vietnamese teachers' perspectives and perceived support during the COVID-19 pandemic. The analysis of the e-survey conducted with 2500 teachers revealed that teachers have had to face various types of financial, physical, and mental struggles due to COVID-19. More specifically, most of the participants stated that they have suffered more from the workload in this period, which has led to stress in their lives (Vu et al., 2020). Failure to maintain the work-life balance due to working from home was also mentioned as one of the key reasons that has led to burnout especially among parent teachers. This situation has been defined as "The mental load that parents carry - for mothers, often disproportionately,which eventually leads to resentment, burnout, and frayed patience" by NYU Langone Health (2021). The study conducted by Hermann et al. (2020), for example, revealed that the shift to online learning in the pandemic period intensified the roles of parent-teachers. This result was supported by Kress et al. (2021) who surveyed 7,841 teachers in the United States and reported that $40 \%$ of the participants had difficulty in maintaining their work-life balance during the online education process due to their caretaking responsibilities at home.

There are relatively few studies that have focused on how academic teachers in different countries have transitioned to online education during the COVID-19 pandemic. Dolonen et al. (as cited in Damşa et al., 2021) investigated the experiences of 826 academic teachers in Norway after the first semester of pandemic teaching and found that they need support from the colleagues and administration (as well as IT support) because although they managed to adopt new technologies immediately, they still spent more time with teaching preparation and found the learning methods less interactive in the online platforms. A number of studies in Turkey, too, examined the experiences and perceptions of teachers in/towards online education process during the Covid-19 period and reported similar results. Having looked into the views of the teachers from various branches towards the effects of Covid-19 pandemic in the education process in 
Turkey, Karakaya and his colleagues (2020) demonstrated that although the teachers accept that the pandemic process has provided the teachers with positive acquisitions in technology use, awareness and skill development, they still have concerns about health, economy and education. Similar concerns have been voiced by the private university ELT teachers, who stated that even though they maintain their positive attitude towards online teaching, they have experienced a lack of technical equipment for virtual classes, an increase in the workload, and a lack of financial support by the institution (Şener et al., 2020). Similar findings were revealed in a local study conducted by Silman-Karanfil and Can (2021) in the same setting with this study in Northern Cyprus. They stated that although English language teachers in a higher institution had to experience the uncertainty and chaos brought by the COVID-19 period, they saw that struggle as an opportunity to grow.

\section{Methodology}

\subsection{Research Design}

The aim of this small scale research study was to investigate the experiences of English language teachers working at the tertiary level during the online education process in the Covid-19 pandemic period. This objective makes this study a qualitative one because as Creswell (2007) stated, it entails "inquiring into the meaning individuals or groups ascribe to a social or human problem" (p. 37). Moreover, achieving the aims of this study requires an in-depth analysis of the data including organizing, accounting for and explaining the data; in short "making sense of the data in terms of the participants' descriptions of situations" (Cohen et al., 2007, p. 461); therefore, this study adopted a qualitative perspective of data collection. More specifically, this research study can be considered as a case study as it intends to look into the complex nature of the teacher experiences in the pandemic period based on the specific contextual factors (Harrison et al., 2017).

Qualitative researchers who want to look at a complex phenomenon from different perspectives may need to use more than one method to collect data. In line with its aim, this research study adopted the multimodal approach, mainly visual methodology. Visual methods are generally used to enhance the richness of the data evoking deep emotions, memories and ideas (Pain, 2012). The use of digital photography and images, for example, enables people to capture and reflect on their emotions through a visual tool (Marin \& Roldan, 2010). Also called as photo elicitation technique or auto-photography, using photography in research studies can be considered as a metaphor study, too. Black (1954) argues that a metaphor acts as a lens or a filter, through which the new reality is viewed and understood. When metaphors are combined with the visual aids such as photography, they offer "a means to build and explore non-linear relationships between individuals and ideas using polymodal hypertextualities" (Loveless \& Griffith, 2013, p. 395). Therefore, the inclusion of multimodality in the present study was intended to provide a more comprehensive understanding into the experiences of English language teachers teaching at the tertiary level in a Northern Cyprus context in the pandemic period.

\subsection{Research Setting}

This research study was conducted in the Northern Cyprus branch of a prestigious public university in Turkey. The medium of instruction is English in this institution, so the students have to prove their English proficiency before they start their undergraduate studies. When the students cannot pass the proficiency exam prepared and administered by the university or provide an equivalent result from the widelyrecognized standardized English tests such as TOEFL or IELTS, they need to attend a one-year intensive English program that focuses on grammar, reading, listening and writing in The English Preparatory Program (EPP), a unit in the School of Foreign Languages. In this preparatory program, the students are equipped with the necessary skills to follow their undergraduate studies in English easily.

When the students pass the proficiency exam, they have to take the compulsory English courses (ENGL 101 Development of Reading and Writing Skills I, ENGL 102 Development of Reading and Writing Skills 
II, ENGL 211 Academic Oral Presentation Skills, ENGL 311 Advanced Communication Skills) for undergraduate students offered by the Modern Languages Program (MLP), the other unit in the School of Foreign Languages. These courses are designed to improve the students' reading, writing and presentation skills further building up on the work of The English Preparatory Program. Other aims of the Modern Languages Program are to ensure that learners can actively apply these skills in post-graduate activities or international contexts, and to raise ethical, innovative, inquisitive, communicative, and creative individuals capable of solving problems objectively, constructively, and critically.

During the Covid-19 pandemic period, along with others, this institution, too, switched to remote learning and started to present the educational content in online platforms. Although the materials, curriculum, and assessment tools were coming from the main campus in Turkey until the pandemic period, since the learner profiles and the expectations of the staff of both programs are quite different, the EPP in Northern Cyprus decided to follow a different path in 2020-2021 academic year, which means it would not follow the exact curriculum and materials with the main campus during the distance learning process.

The platforms used can be divided into two groups as online conferencing tools and online teaching \& learning tools. As for the online conferencing tools, both programs have used Zoom and Webex for the synchronous lessons. Webex was adopted as the official online platform by the School of Foreign Languages to administer online quizzes or exams and to have the online lessons, but some instructors used both platforms interchangeable according the facilities they offer. In addition to the online meeting tools, In the Modern Languages Program, the online version of the book "Q Skills" has been used to provide the students of the ENGL 101 Development of Reading and Writing Skills I course with a blended learning experience with activities that include video, vocabulary, grammar and skills practice, grammar and vocabulary games or online discussion boards. In the English Preparatory Program, on the other hand, Off2Class, which is an online tool that comprises teacher-led online ESL lesson content, was used as the main curriculum content. In order to support the curriculum in terms of reading, grammar and writing, the online tools called ReadTheory and Quill were also integrated into the program.

\subsection{Participants}

The participants of the present study were chosen on the basis of non-probability sampling because they were chosen among the teachers who shared some important experiences relevant to the study to conduct an in-depth analysis (Cohen et al., 2007). Seven participants, both from MLP (Modern Languages Program) and EPP (English Preparatory Program) took part in the study. The teaching experience of the participants ranged between 6 and 20 years. Six participants were female and only one male took part in the study. Three of these participants were married, and they were parent teachers, who were dealing with their kids at home during the day since the schools were closed due to the pandemic period. One of the participants was the teacher trainer, who was responsible for preparing and implementing teacher development activities for the in-service teachers. Three teachers had administrative duties such as course designing and taking care of student affairs in the program. Another participant was the director of the School of Foreign Languages, who was responsible for supervising the teaching-related activities in both programs mediating between the higher administration and the teachers and two participants were actively pursuing their academic careers. Bearing the ethical issues in mind, the participants were assigned pseudonyms and they will generally be referred as "s/he" in order to maintain anonymity. The brief overview of the participant profile can be seen in the table below. 
Table 1.

The participant profiles

\begin{tabular}{|l|l|l|l|l|l|l|}
\hline Participants & Age & Gender & $\begin{array}{l}\text { Marital } \\
\text { Status }\end{array}$ & $\begin{array}{l}\text { Teaching } \\
\text { Experience (years) }\end{array}$ & $\begin{array}{l}\text { Educational } \\
\text { Degree }\end{array}$ & $\begin{array}{l}\text { Professional \& Administrative } \\
\text { Roles }\end{array}$ \\
\hline P1 & 41 & F & M & 16 & MA & Course Leader \\
\hline P2 & 41 & F & M & 18 & $\begin{array}{l}\text { School of Foreign Languages } \\
\text { Director }\end{array}$ \\
\hline P3 & 50 & F & S & 29 & MA in progress & In-service Teacher Trainer \\
\hline P4 & 29 & F & S & 6 & PhD in progress & None \\
\hline P5 & 51 & M & S & 30 & PhD in progress & $\begin{array}{l}\text { Administrative \& Student Affairs } \\
\text { Unit }\end{array}$ \\
\hline P6 & 31 & F & S & 8.5 & MA in progress & None \\
\hline P7 & 38 & F & M & 13 & BA & None \\
\hline
\end{tabular}

\subsection{Data Collection Tools}

As part of the data collection process, the participants were asked to complete a demographic info survey and the "Auto-photography" task (see Appendix 1), which was adapted by the researcher from "Picture This Project" developed by Hamilton (2016). In this task, the participants were supposed to use photos and words to define, through their eyes and in their own words, their perceptions and experiences in the remote learning and teaching process during the Covid-19 pandemic period. More specifically, in this task, the participants were presented six themes (work-life balance, professional development, academic activities and research, collaboration and communication among colleagues, relationship with the administration, and online teaching) among which they choose four to reflect on. After choosing the themes, they were required to take a picture that, for them, summarizes the whole idea of each topic chosen. Due to ethical concerns and principles of consent, participants were asked to avoid taking pictures of others. These photos were also accompanied by the short written abstracts (120-150 words per abstract) in which they described and discussed the image reflected their ideas or experiences related to that specific theme.

In addition to the auto-photography task, focus group interviews were conducted in order to collect data

in a more detailed way. More specifically, the researcher showed some of the pictures to the participants to collect further data and asked for clarification or more details based on the abstracts accompanying the pictures. The data obtained via the interviews were particularly useful in this study as they provided indepth insights on participants' attitudes, thoughts, experiences, and needs regarding the online education process they have been involved in for about a year (Dörnyei, 2007).

\subsection{Data Collection and Analysis}

The participants were contacted via e-mail and asked to complete the auto-photography task in two weeks. They were also informed that the researcher may invite them for an interview to discuss their experiences further. The collected data from the task was exposed to content analysis as the aim was to analyze the written and visual data by summarizing and reporting the main content to make valid inferences about the message given in the data, the sender of the message, the audience, and the social context in which the message is created (Beach et al, 2009; Cohen et al., 2007; Weber, 1990). In line with this aim, the research analyzed the completed tasks and reflections of the teachers to identify the words used to describe the themes from their perspectives, as captured through digital images, as well as the ways in which participants wrote about, discussed, and reflected on their ideas on the themes provided with them. In this phase, to have a deeper understanding into the issues, word choices in the expressions related to the themes were investigated as the word choices might show how the author feels about that specific theme and they can reveal the author's tone or attitude (Taylor, 2019). More specifically, the participants' photos were examined along with the abstracts accompanying the visuals. Open or inductive coding was applied in data analysis, which means the researcher initially analyzed and coded the data based on the visual and textual 
metaphors used by the participants and the ideas meant with those metaphors (Creswell, 2008). After the initial coding, the researcher reread the data and applied the codes using constant comparing and contrasting approach. Additional codes were created when the existing ones did not match some of the ideas presented. This was repeated until all the data were compared, coded and grouped according to similar concepts and ideas (Strauss\&Corbin, 1998).

For the focus group interviews, the participants who share similar characteristics (having a child, having extra teaching-related responsibilities, teaching experience) and mention similar points in the task were grouped together. Since there were coronavirus precautions on campus, the participants were contacted and interviewed via online platforms on two different days. The interviews were conducted in English in order to avoid any loss in meaning during the translation process. They were video-recorded so as not to lose any data upon getting the consent of the participants. Each interview took approximately an hour. During the interview, the researcher asked some follow-up questions to enable further exploration of the themes in the task and clarify any unclear points mentioned by the teachers in their abstracts. Upon the permission of the participants, the researcher showed some of the pictures taken by the participants during the interview so that the participants can inspire each other.

In order to ensure the validity of the present study, the researcher exploited certain strategies such as using more than one method in the data collection and analysis process and thick description of the setting and the participants (Bashir et al., 2008; Creswell \& Miller, 2010). The use of these strategies enabled the researcher to get a wider perspective into the situation and ensure the correctness of the findings as the researcher's aim was to help the readers to decide if the findings of the study are applicable to other contexts. The researcher employed certain strategies to enhance the reliability of the study, too. Firstly, no biased questions were asked to the participants during the interview. Then, after the data were transcribed, coded and categorized into groups, the results were shared with another researcher to be checked from a different perspective. Ethics were ensured and maintained throughout the study. First of all, the researcher applied to the Scientific Research Ethics Committee of the university to get permission to collect data from the teachers. Upon taking the approval from the committee, the participants were informed about the aims of the study and the researcher made sure that the participants voluntarily took part in the study. Moreover, in order to ensure the anonymity of the participants, the researcher avoided using any information that might be traced to the identity of the participants in the study.

\section{Results}

The examination process of the symbolic digital images English language teachers took and shared, the accompanying reflections and transcripts of two focus group interviews showed that the teachers who took part in the study had different and shared perspectives and experiences regarding the online education process Covid-19 period. In this section of the paper, the findings of the study are presented in six themes, mainly as (1) work-life balance, (2) professional development, (3) academic activities and research during the online period, (4) communication and collaboration among colleagues, (5) relationship with or support from the administration, and (6) online teaching or the use of online tools.

\subsection{Work-life Balance}

A common view among the participants related to work-life balance was how imbalanced their lives became due to working from home. For the teachers, the reason for this imbalance was wearing too many hats; in other words, having too many responsibilities at the same time. They stated that they have been trying to be a teacher and work from home, deal with the house chores, take care of the kids at home, get into and follow a routine and stay sane all the same time, which has led to burnout from time to time for them. The picture P7 shared for the study (Fig. 1) and her/his reflection on the topic summarizes what teachers have experienced during this period: 


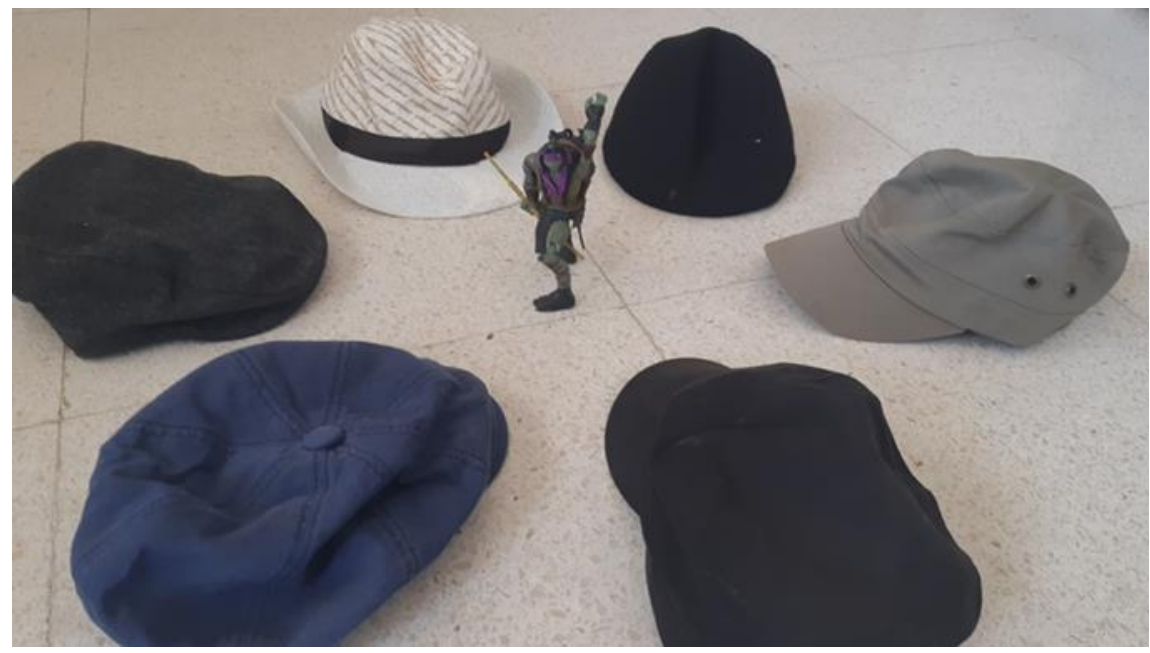

Fig.1. "A hero with too many hats" $\mathrm{P} 7$.

"I took this photo because I believe it describes how I feel during these unfortunate times. Each hat describes a role of mine, and the ninja in the middle shows how much of a hero I have to be to deal with all of the responsibilities at the same time." (P7)

It can be seen in the excerpt that the teacher feels the challenge to deal with all the responsibilities s/he has been faced with in this period. Surrounded by work or home-related duties, s/he is quite concerned that s/he will fail at some point as $\mathrm{s} / \mathrm{he}$ thinks that $\mathrm{s} / \mathrm{he}$ has to be a hero to manage all these. P1 shared a similar concern and a reason for the imbalance teachers experience. As a working mother, she focused on the blurred lines between family life and work duties nowadays as the main reason for the difficulties in balancing work and life:

"I think what makes things so complicated and challenging is about the boundaries; we don't have any anymore. They are all blurred and mixed together. You can't leave work at work and go home. So, we have meetings in the evening, or we have e-mails to answer all the time. Students can e-mail you anytime! Home is your office now, but you have a family to care of, too." (P1)

The most salient experiences that show how work and life have mixed focused on how teachers were dealing with the school and teaching-related duties at home as a 24/7 job. Most of the participants stated that they work at least 14-15 hours a day answering student e-mails or Whatsapp messages from colleagues, getting prepared for the lessons, and giving feedback to the students. Since they work on school-related issues more than usual, they "end up doing house chores between lessons, or answering urgent student, colleague, or admin e-mails and WhatsApp messages while cooking or even getting ready for bed late at night" (P3).

The reason for this chaos in the teachers' personal lives was given as the unknown nature of the online teaching period, especially at the beginning. Since teachers had had no such experience beforehand, they did not know how to face the new duties and responsibilities in the right way. However, interestingly, despite this uncertainty mentioned as the main source of challenges, the majority of the participants stated that they were quite optimistic and excited about the online education process at the very beginning, right before the emergency remote teaching period started on 16 March 2020. To explain how things have changed so far for the teachers, especially the ones who were relieved when the decision for the online education was made, $\mathrm{P} 4$ used the picture of a sagging chair and reported: 


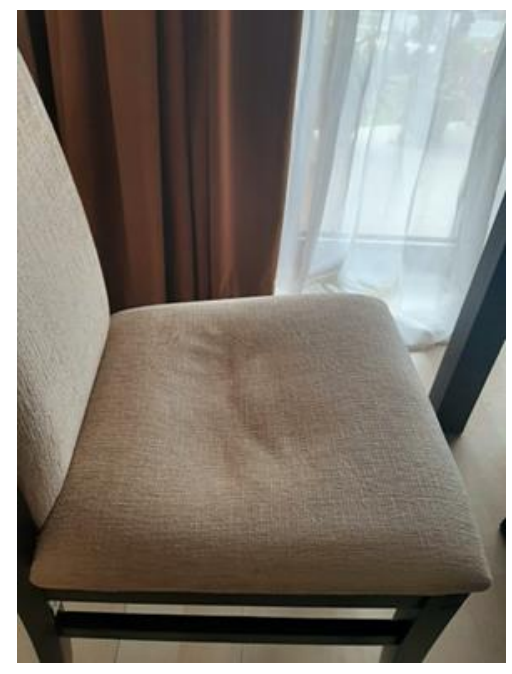

Fig.2. "Pain in the ass" (P4)

"Working from home was something we had been seeing in our coursebooks and I was like "Wow, look at these people! How flexible they are. It must be really nice to work like this..." Although the idea of "flexibility" and "working from your happy place" sounded quite charming at the beginning, I later realized that it was only the honeymoon stage. Similar to the feeling you get when you sit on a comfy chair, you get the sense of comfort and flexibility only at the beginning. Then, with all the tensions, difficulties, challenges, the unknown and the uncontrollable, you lose the sense of work-life balance and it turns into a real trouble, or pain in the ass" (P4).

The picture and the accompanying abstract show that although teachers idealized working from at the beginning, the situation did not turn out as they imagined it to be. As pointed out by other participants, too, they used to dream about working from home-office thinking that they would work in the comfort of their home, concentrate better, and have the chance to arrange work time flexibly, but happened in real life was described as a nightmare by P1.

The conditions were especially difficult for the teachers who had little children at home. After the schools were closed due to the Covid-19 measures, the children could not go to school, and they started to receive online education in front of the computers at home. That meant for some teachers to keep an eye on their children even when they are actively teaching a class. Although these parent-teachers had found a balance to be efficient and happy both at work and home under normal circumstances, during face-to-face education, wearing one hat at a time leaving home-related duties at home and work-related responsibilities at the workplace, they lost that balance when the pandemic started, and they had to work from home with the kids getting education online. One of the teachers explained what she has experienced regarding this issue in her abstract as:

"Especially after my son's school was shut, I honestly didn't know what to do and it was very frustrating because suddenly, I was everything: a mother, a housewife and a teacher... I not only have to meet his basic needs like food but also have to make sure he is participating in his lessons and keeping track, which is another difficulty because he has to be convinced every day... in these circumstances, it is not possible to have the right balance between work and life at home because there is no routine and anything is likely to happen in the house, so you cannot switch off and be one of the roles; you are always all of them at once." (P7)

The duties of having a child at home while working as a teacher during the online period doubled when the teacher has certain administrative or extra teaching-related responsibilities. Considering that having such 
responsibilities is difficult enough even in face-to-face education, it is not surprising that teachers feel drained trying to manage the time to work things out both for work and for family or home. The metaphoric image of a derailed train below in Figure 3 and the abstract that accompanied it shows how a parent-teacher with administrative duties at school has been feeling during this period:

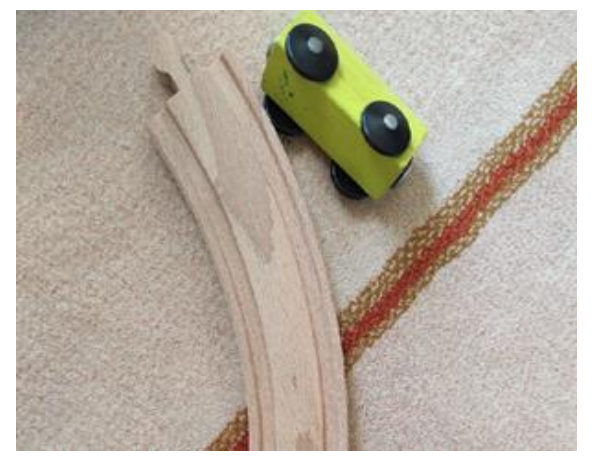

Fig.3. "Derailed" (P.2)

"My life is derailed! I chose this picture as it describes how I feel. The pandemic hit me hard. I've lost balance, and I'm not on track... I am a parent 24/7; I am at work 24/7 and a wife 24/7: I attend a meeting while cooking dinner, I resolve family issues while texting about work, I tell my child off for watching too much $\mathrm{TV}$, while I'm making an important decision about work and my phone rings while I'm on holiday with my family." (P2)

Although one of the participants mentioned that things are not as complicated as the time of emergency remote teaching thanks to the experience teachers have had and more structured practices, many others reported their on-going frustration with online education, stating that they are half of everything, but not fully successful at any.

\subsection{Professional Development}

Opinions and experiences differed among the participants as to the professional development of English language teachers during the online education process. While some of the participants focused on the opportunities and growth points, others mentioned the challenges. The opportunities stated by the participants included improving soft skills such as empathy and the abundance of professional development opportunities online. To start with a broader perspective into the opportunities brought by the online education period, one of the participants pointed out that the challenge of teaching online actually made this process an opportunity for professional development. Using the picture of a shadow that made the person look taller, s/he metaphorically referred to how much people can grow even the source of light in their lives, in this case, their routines or what makes them successful under normal circumstances, is taken away from them because they eventually end up trying to find new ways to sort things out. This is explained in the participant's excerpt as follows: 


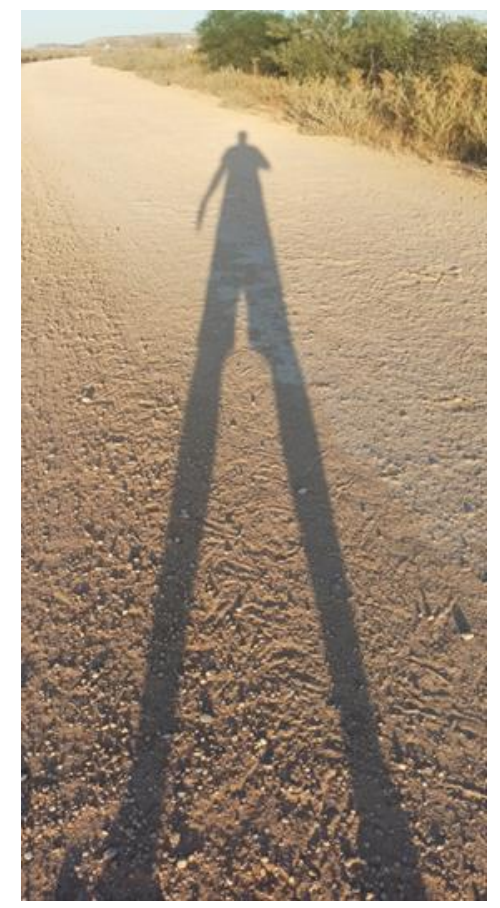

Fig.4. "As the heat declines, the shadow grows" (P5)

"The idea is that when you face challenges, you grow more. We are generally fed by the sun's energy, but when it starts to go down, I mean when things go wrong for us, we actually grow as in the picture. Suddenly, we had to face the challenge of online education, and we had to find new ways of teaching, new ways of testing, and this leads to professional development. This is professional development for me. When everything is alright, we don't feel the need to grow; you need to face some difficulties."

This idea was further supported by another participant who focused on the professional development activities, conferences, courses, certificate programs, or training options available online for teachers all around the world. The photograph presented in Figure 5 was used by this participant to represent the abundance of the opportunities for professional development of the teachers. The abstract that accompanies the picture shows that it is not only about the variety or the abundance of these opportunities but also about flexibility and convenience.

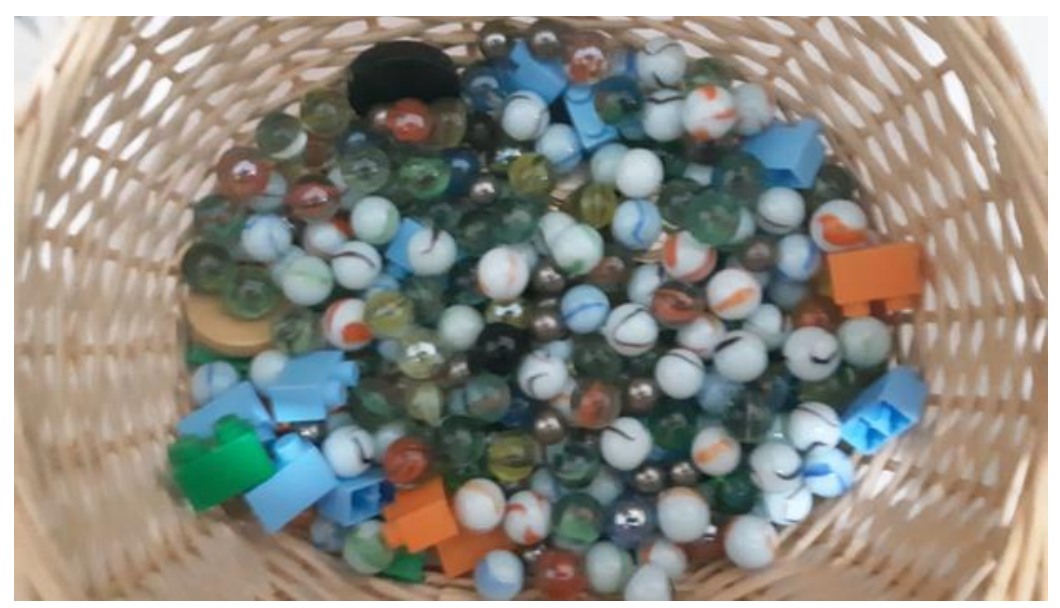

Fig.5. "Opportunities for improvement" (P7) 
"These marbles and legos show how much variety and opportunities we had to improve ourselves and develop professionally... Since we cannot travel and we do not need to go to school, as long as it doesn't coincide with our lessons, we have the opportunity to join a course or a seminar from home at a suitable time for us... I didn't have to arrange everything and leave the house or make sure my passport is valid. All I had to do was to open my laptop and join a Zoom session."

Apart from the opportunities available online, improving the soft skills as part of professional development was also touched upon by some participants. They stated that since they go through the same challenges with the students, including work-life balance, health issues, and psychological problems, they feel more empathetic towards the students, affecting their teacher-student relationship positively. This was reflected by $\mathrm{P} 4$ as follows:

During this period, I have started to be able to sense and empathise with students more than ever. By paying much more attention to their realities (physical/ emotional health, feelings, ideas, preferences, attitudes and opportunities/ challenges -economic, psychological, social, cultural etc.-), I feel that I have been growing into a more empathetic, understanding and mindful person and teacher. (P4)

Despite the opportunities mentioned by some of the participants, there were also some teachers who stated their frustrations, reservations, and concerns related to their professional development during the online period. The in-service teacher trainer who took part in this study, for example, reported that s/he also had difficulties, especially during the emergency remote education, because s/he was both the one who was expected to offer support to the teachers and the one who needed help as a teacher. Having been under constant pressure by the administration to do something to help the teachers, s/he conducted a needsanalysis with the teachers to understand what they expected from the PDU during this process, sent questionnaires, held share-care sessions, and had many meetings both with the teachers and the administration. However, $\mathrm{s} / \mathrm{he}$ said that $\mathrm{s} / \mathrm{he}$ felt frustrated as what $\mathrm{s} / \mathrm{he}$ had done was not appreciated by the teachers. The picture s/he shared along with her/his reflections explains how hard s/he tried to "get in" the teachers' professional development territory to support them as a teacher trainer.

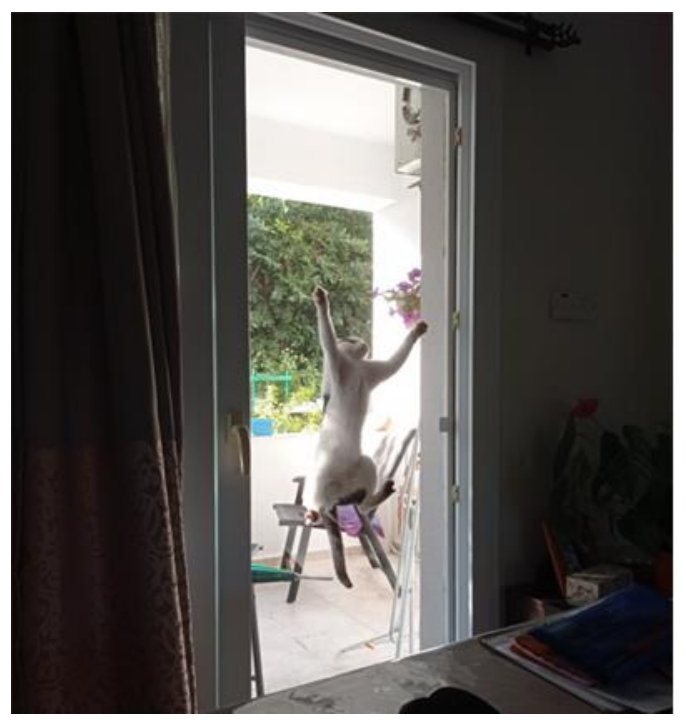

Fig.6. "Let me in" (P3)

"Neither the shock of switching to online teaching, nor the responsibility of having to provide support challenged me as much as the resistance from teachers to developmental activities. Just like the cat in the picture, we were trying to get in, and we felt a bit frustrated." 
In addition to the frustrations, lack of time and energy was also mentioned by one of the teachers when asked about professional development during the online education process. S/he reported that the increased workload and the screen fatigue were already tiresome for her/him, and s/he needed to spare the time left for her/his family or her/his well-being. S/he said:

"Who has the time for professional development anyway? Even if I have the time, I wouldn't like to spare it for more online activities because I really need to stay sane. We need some space away from the screen. Yes, we have a lot of opportunities, but do I want to use those? Well, not now."

\subsection{Academic Activities and Research}

Regarding the academic activities during the online education process, there were both positive views or experiences and the challenges mentioned by the participants. Starting with the opportunities or benefits, one of the participants stated similar ideas with the ones mentioned in the previous theme. S/he said that thanks to online education in the Covid-19 pandemic period, new research areas became available, especially in the field of online education (tools, testing, teaching). Moreover, many universities around the world gave access to their resources for those who want to do research, and lots of online conferences, which the teachers would not have been able to attend under normal circumstances, have been held. Therefore, s/he used the picture of a pomegranate to metaphorically refer to the plenitude of the opportunities offered to the researchers or teachers trying to pursue their academic activities.

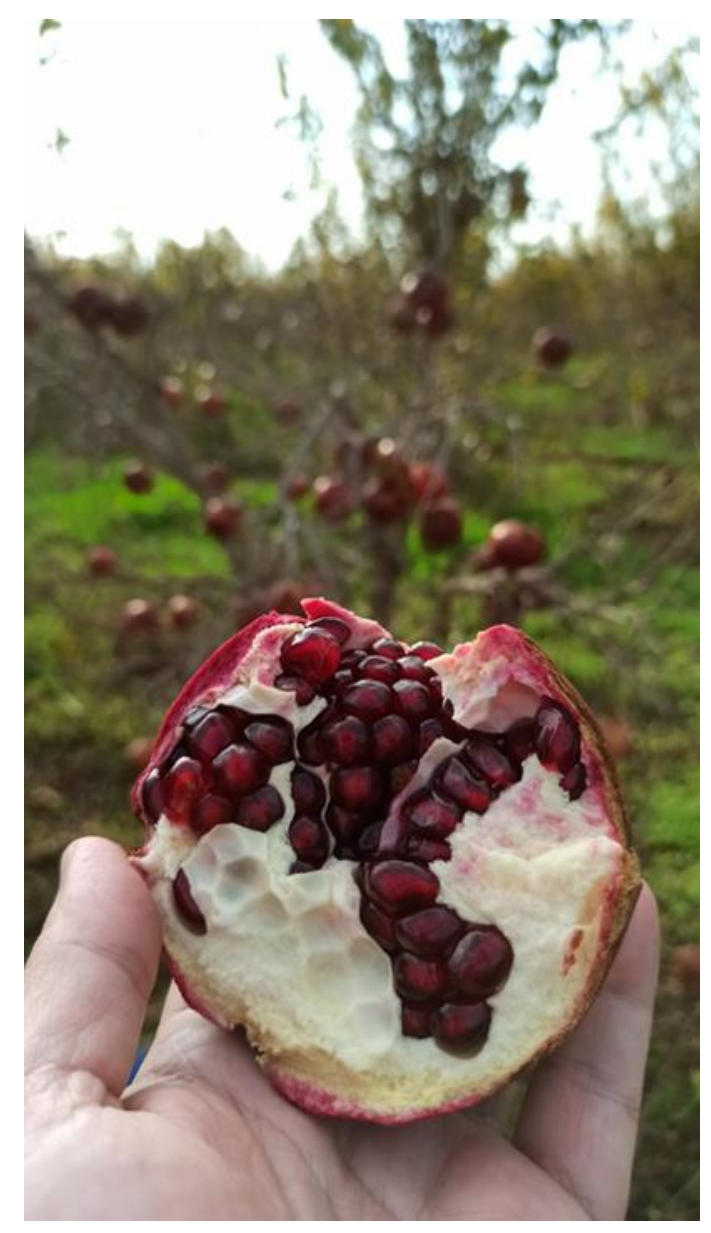

Fig.7. "The Good Red” (P5) 
Similar positive views were shared by $\mathrm{P} 4$, who was following her/his $\mathrm{PhD}$ studies during this period. S/he indicated that she felt lucky taking her PhD courses online without commuting to another university, one or two hours away from where she lives. On the other hand, another participant, who was trying to finish her MA thesis, stated that since the beginning of the pandemic period, s/he had faced many challenges such as difficulties in collecting data, loss of motivation, and increased workload interfering with the academic studies. Considering the experiences s/he has had as a researcher during this process, s/he used the photograph of wilted flowers to show how s/he has been feeling lately and explained her/his emotions as follows:

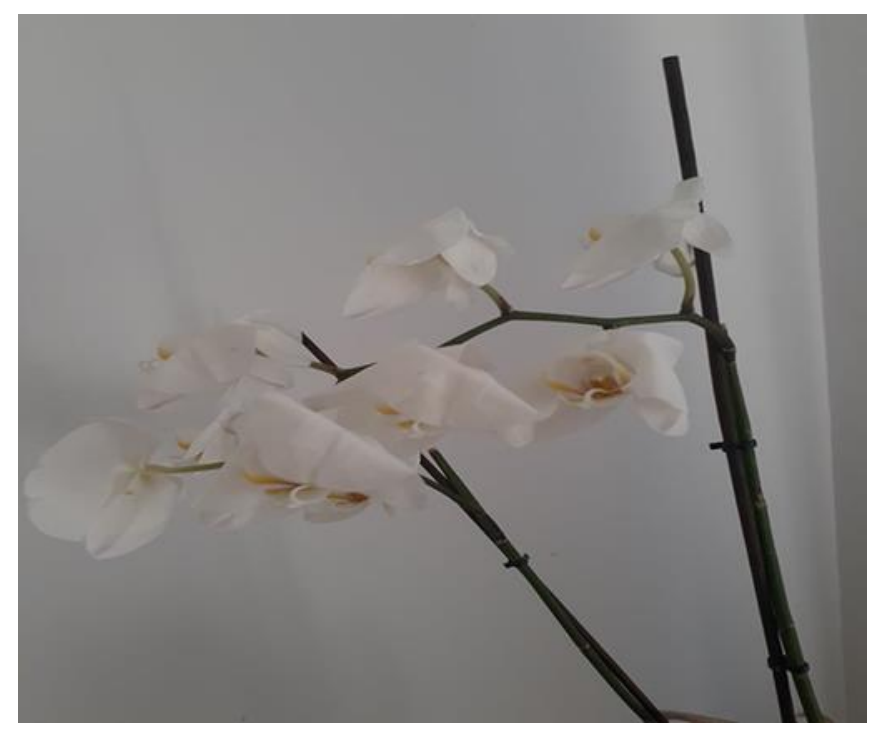

Fig.8. "Fading like a flower" (P6)

"Before this period, I believe I was more motivated and energetic to focus on my research and improve myself just like the flowers starting to bloom and grow. However, because of some factors such as the increase in the workload, lack of motivation among students as well as some other concerns related to the pandemic, I think carrying out academic activities and research has been very challenging, tiring and emotionally draining. "(P6)

The P1 shared similar experiences. S/he reported that right before the Emergency Remote Education period started, s/he had been getting ready for a visit to Turkey to take the Academic Personnel and Graduate Education Exam (aka ALES), which was necessary for her/him as a Turkish citizen to apply for a PhD program in Northern Cyprus. However, due to the travel restrictions, s/he couldn't sit the exam and naturally could not apply for the $\mathrm{PhD}$ program. S/he explained how hard s/he tried to do something to sort it out, but her/his efforts were in vain in the excerpt below:

"What I was asking for was a special treatment due to the conditions. I even went to the embassy to talk to the representative of Turkey for education. They just sent me away."

In the focus group interview, another participant agreed that under unexpected circumstances, the educational policies should be implemented accordingly and considered this situation unfair to the ones who want to pursue their educational rights, which was regarded as a complete flaw in governmental educational policy (P2).

A striking suggestion made by one of the participants (P2) was "leaving a mark" for future generations by engaging in academic activities. By academic activities, what was meant by the P2 here was documenting whatever experience, concern, achievement, or failure we have had in this online education process. S/he stated that having this in mind, s/he conducted a study on teachers' perspectives towards the online 
education process or practices in her institution. S/he explained her/his rationale with the picture (Figure. 9) and the accompanying abstract below:

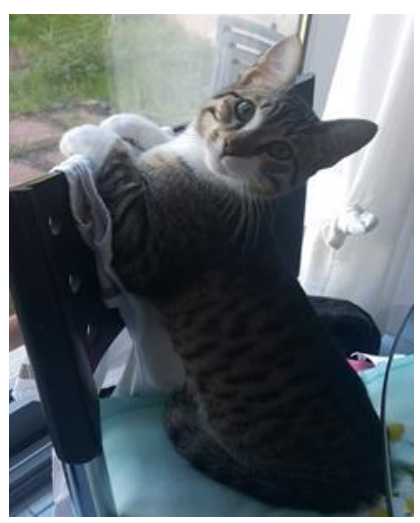

Fig.10. "Leave a mark"

"It's our responsibility to leave a mark for the future generations. I chose this picture as cats will mark their territory when they feel threatened, stressed or anxious... I guess that's how I feel and I do not want future generations to suffer in the same way. So I want to leave a mark by sharing data." (P2)

\subsection{Communication and Collaboration among Colleagues}

Regarding the collegial relations during the online education process, most participants agreed that it was difficult to get in touch, communicate and find a middle ground with the colleagues at the beginning during the emergency remote education process, but things got better in time. The participants stated that they had limited contact with colleagues at the beginning because no one knew what they would do, and they needed space considering the health crisis newly emerged at those times. However, as some participants mentioned, this limited contact turned into a unique collaboration among colleagues, which they did not have this much in face-to-face education. One of the participants, $\mathrm{P} 4$, reflected on how s/he felt at the beginning and the transition period of the collegial relations by using a mask metaphor:

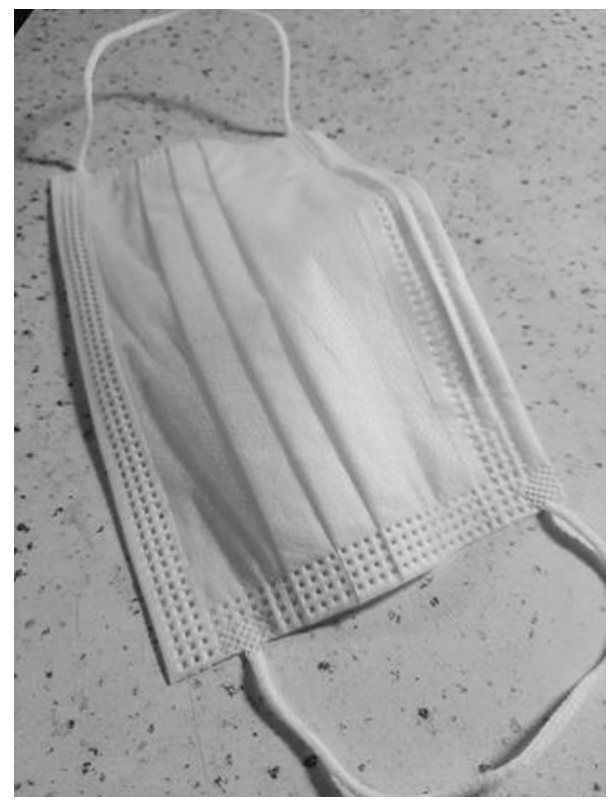

Fig.11. "The Maskeeters" (P4)

Similar to the masks we have had to wear since the emergence of the pandemic, the communication with our colleagues seemed masked to me. Due to this distance, I felt 
quite alone professionally and have had some hard times at the beginning. However, in the course of time, this masked relationship has turned into "a musketeer relationship" where we learn, think and function together as the soldiers in the French novel, The Three Musketeers.

Sharing similar experiences, another participant (P3) expressed what s/he has gone through in this process in relation to collaboration among colleagues through the metaphor of baking bread with no prior experiences. S/he stated that learning new skills during the online education process was like baking bread for her/him because s/he didn't trust her baking skills beforehand, but during the quarantine, s/he managed to do that with the recipes s/he got from her/his friends as s/he felt the need and motivation to bake bread at that time. Similarly, as s/he mentioned, although s/he started online teaching with no experience in the requirements, qualification or knowledge on online education, s/he managed to learn how to navigate herself when teaching online with the guidance coming from colleagues. To express what s/he has gone through in this period, s/he stated:

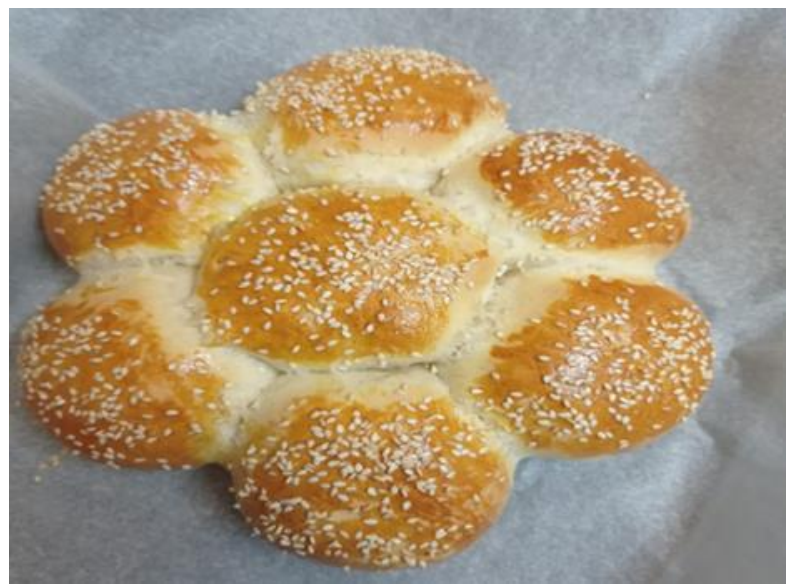

Fig.12. "I didn't think I had it in me!" (P3)

"In face-to-face education, as experienced teachers, we knew what we were doing, so we didn't need collaboration that much, but when we started teaching online, everyone was in a huge panic. We had no idea how to screencast or prepare materials for online teaching, so we all panicked. Then, we realized that there were people who were techsavvy and ready to help us. I think we all developed one way or another because of collaboration. It reached its peak during this period!"” (P3)

When asked how the nature of the relationship among colleagues changed from being distant or reserved into a highly collaborative one, one of the participants focused on the emotional support teachers received from each other during this period:

"I guess we got the sense of "we are in this together." We realized that we need collaboration more than ever. Support has become more important for us because our emotional needs were not that obvious in face-to-face education (P4)."

However, the relationship dynamics have not made all teachers satisfied during online education. For example, one of the participants described herself/himself as "trapped" when teaching online from home because s/he has been away from her colleagues and therefore, s/he communicated and collaborated less than s/he had done in face-to-face education. In her/his abstract and during the focus group interview, s/he explained the reason why s/he felt like that by focusing on the social aspect of the teaching profession for her/him: 


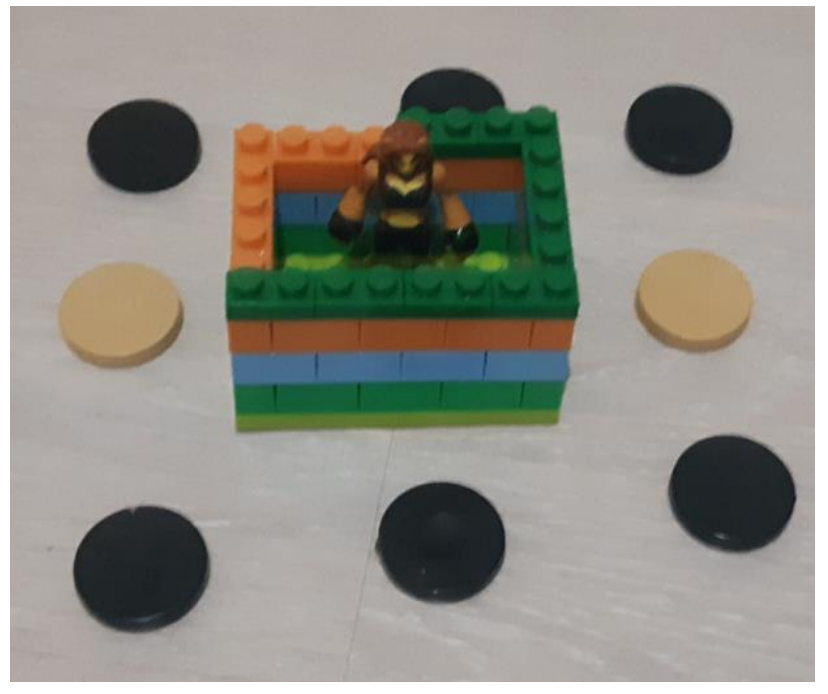

Fig.13. "Trapped in a box with very little connection to our colleagues" (P.7)

"When we were teaching face-to-face at school, we had a very collaborative, communicative and friendly environment. Therefore, going online, gave us the feeling of isolation and loneliness... it never gave the same satisfaction as it used to. This is because at school, it wasn't only about sharing materials or ideas about teaching methods. While communicating about anything, we shared moments where we laughed, got angry or even cried together. Sometimes a friend appeared at the door offering coffee just for me to take a break. I miss everything about being at school. Therefore, lacking these moments never give me the same feeling of collaboration and communication."

\subsection{Relationship with or Support from Administration}

Regarding the relationship with the administration, all the participants shared the common belief that they did not get enough support from the higher administration of the university and felt ignored, which affected teachers' sense of belonging with the institution negatively. The participants mainly explained how they felt lost and abandoned by the higher administration, especially at the beginning of the online education process when they hardly received information on what is supposed to do and how. One of the participants used a picture of a tree and a cat stranded to refer to that difficult period. S/he mentioned what they experienced at that time as follows:

"With the announcement of going online we all went "hurray, let's climb that beautiful tree." However, there was no guidance or help coming from the administration. They just said "climb" without giving any instructions to how high we should climb or how we should get down afterwards" (P5). 


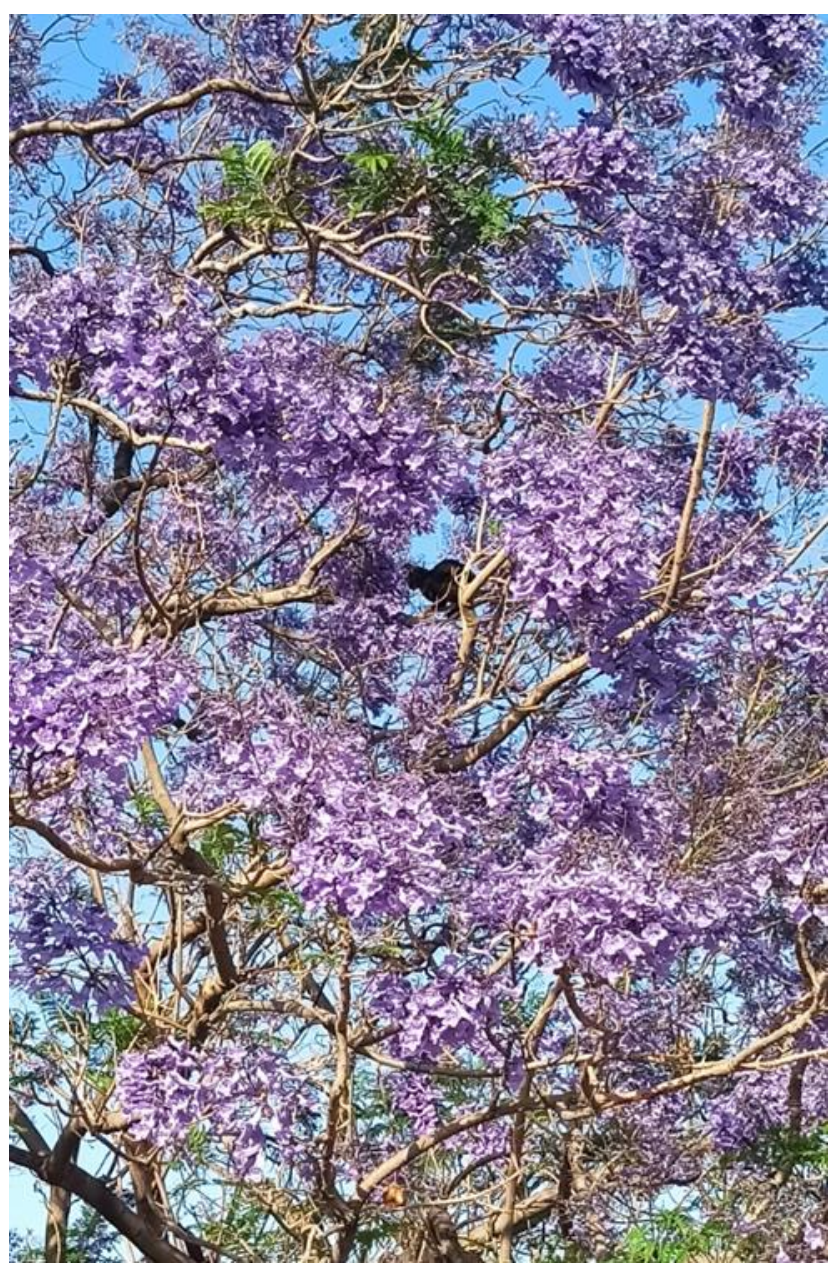

Fig.14. "To jacaranda or not to jacaranda" (P5)

Focusing on the emotional labor aspect of that situation, another participant stated s/he could not feel safe as a teacher at this institution anymore due to the uncertainties. As mentioned by other participants, too, what was expected from the administration was mostly nothing more than showing empathy by saying "We got you! You are not alone!" as noone was expecting to be provided with everything they needed in a very short time (P1).

One of the participants (P2) approached this lack-of-communication problem between the teachers and the administration from a broader perspective and stated that the school administration is not the only one to blame for the lack of communication or transparency:

"I think the problem here is everybody was slow in this process. YÖK (The Council of Higher Education in Turkey) was slow in announcing everything. YÖDAK (Higher Education Planning, Accreditation and Coordination Council in Northern Cyprus) was slow. Moreover, unlike other governments around the world, our government took so much time to make an announcement of what to do, and when they finally made one, YÖK said something like "Each university should do whatever they can within their infrastructure" in a vague way. If the administration had explained this to the teachers, things would have been clearer. I guess they should have been more reflective and transparent."

When asked what kind of support they expected and couldn't find from the school administration, the participants mentioned the need for technological tools such as cameras and laptops. They stated that some teachers suffered from a lack of the devices (e.g., camera, microphone, headphone, etc.) necessary to teach online, and it was really difficult for them to buy even a mediocre laptop considering the high exchange 
rate between euro or dollar and TL. The extract below shows how lonely teachers felt when they got no support from the administration regarding the technological tools:

"We needed help especially in terms of technical tools. Some people had no cameras or laptops. They were told to get them by themselves. There was no financial contribution from the school at all. (P5)"

Like P5, other participants emphasized the financial struggles they have gone through during this online education process. Some stated that they had to buy laptops and cameras, and what they expected from the school administration was actually to find and make an agreement with a place where the staff could get whatever technological tools they needed with discounts. Still, it did not happen although this suggestion was made to the administration. The participants even reported that the administration deducted their summer school salaries on the ground that they were teaching from home even though the teachers were using their own electricity for teaching purposes. Concerning this issue, one of the participants said:

"Nobody talks about the electricity bills... Last month, I paid 1000 TL because I am constantly at home, my only means is AC to keep warm, and my computer is working 24/7. It was the highest I have ever paid in my life for electricity. Meanwhile, the school administration is not paying for anything in the school nowadays regarding electricity, heating, water, or even toilet paper. It is just unacceptable" (P3).

\subsection{Online Teaching and the Use of Online Tools}

In general, all the participants stated that they had difficulty in terms of online teaching and using online tools, especially at the very beginning, although they got used to how to deal with the challenges in time. One of the participants mentioned the difficulties s/he had while teaching English online as follows:

"Online tools make our lives easier, but it is never the same with face-to-face education. English language teaching cannot be done through online tool. I am not happy at all... We use 3-4 online tools and It is also hard for the students to keep up with what is going on in each of them. Also, when you are teaching and learning online, you have to be very organized cause everything is everywhere. So, I cant keep track of my students all the time." (P7)

Another participant described the difficulty of dealing with many new responsibilities related to teaching and engaging in new practices using online tools as a vicious circle. Considering the situation they were in as a paradox, s/he stated that while on the one hand, they were complaining about the uncertainty in their lives due to the pandemic conditions, they were also trying to juggle everything at the same, bombarded with new things, which led them to be in a quandary again in the abundance of things. S/he further commented on this issue by saying:

"With the introduction of a number of tools, ways of communication and assessment, both the students and the teachers seem to be bombarded with new information... Although what we need is to slow down, understand the needs, care about our physical and emotional well-being, the test fetishism and being too ambitious(!) in terms of academic goals seem to make our job a full(!)-time one in its literal sense" (P4)

When asked why this "test fetishism" emerged and the issue of assessment has become more critical than ever, another participant stated that there was huge pressure on the school administration because the English Preparatory Program in the Northern Cyprus Campus separated the ways from the main campus, which had been regarded as the main authority in relation to educational decisions for years, using a 
different syllabus, teaching materials or tool and testing items, and both the teachers and the administration felt the need to prove themselves (P3). The situation in the Modern Languages Program was not different in terms of assessment. One participant stated that they were also under pressure because they were concerned about the student profile and needs. S/he explained why they were meticulous in preparing testing items and methods as follows:

"The student profile coming from the preparatory school has changed during the online education process. Therefore, we needed to make some adjustments, both because of online education and because of the quality of students. We knew that some students came to the department with very low level of English although they passed the proficiency exam because some of them cheated on the exam. Therefore, the books and the testing changed accordingly." (P3)

Despite the challenges encountered, the participants pointed out that they learned a lot from their mistakes and managed to adapt to the new normal. One of the participants, for example, mentioned her/his experiences as a course leader giving examples from the exams that didn't work, the questions s/he had to cancel from the exams because of a simple mistake s/he couldn't foresee, or the tools s/he planned to use in the class but didn't work in practice. S/he said all these experiences actually turned into an advantage for the teachers as that is how they got used to being prepared for the unexpected things in the class (P1). To explain this bitter-sweet process, s/he used the picture of the stove as a metaphor and reflected on the issue of online teaching as follows:

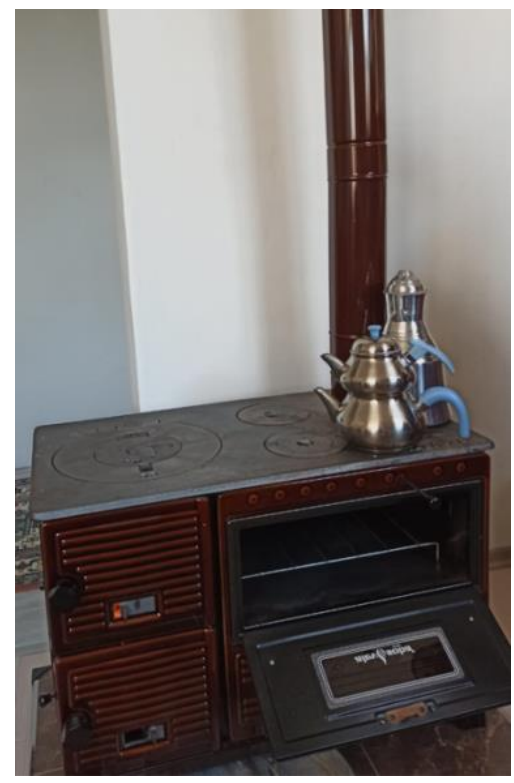

Fig.15. "Chestnut kebab" (P1)

"A stove is quite useful and multifunctional. You can heat the room with it, bake in it or cook meals on it. You can have hot water all day on the stove and you can spice up your winter nights with baked potatoes or chestnuts make on the stove. It is in a way similar to online teaching and using online tools. We have access to loads of various online tools. They can be quite useful in teaching and could make the teaching experience very effective and enjoyable... However, you need to know how to burn a stove and what to burn in it. Before you even try making chestnut kebab, you need to watch someone burn and use the stove and then learn how to start the fire in it and how to keep it burning all day. While learning how to burn the stove, it is highly possible that you will burn a finger or worse... By the way, I can make wonderful chestnut kebab on my stove now but you should see my fingers!" (P1) 
The extract above shows that adaptation to online teaching and using online tools took and required some time, energy, practice, and collaboration, but eventually, teachers managed to survive and even enjoy the whole process despite "still having the pain in their fingers." This view was echoed by another participant who referred to this adaptation process metaphorically using the picture of a chameleon. S/he stated that "teachers are like chameleons in terms of adaptation", and when it comes to online education and using online tools, "It is just a matter of getting used to them". Therefore, what teachers have done in this process was actually "immediately changing their colors when exposed to online tools and don the colors of online education just like the chameleon (P5)."

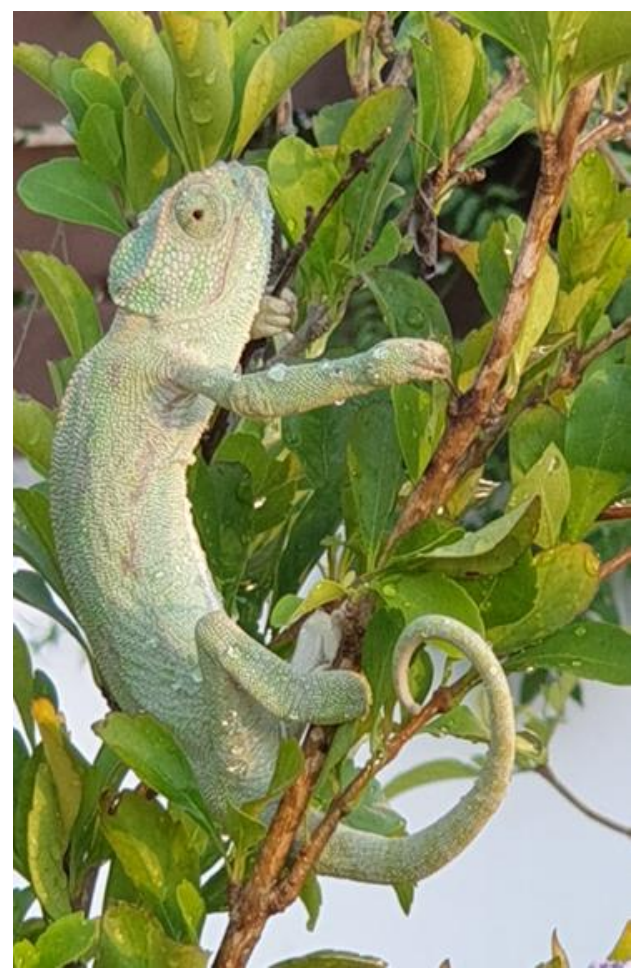

Fig.16. "Pigmented Lives" (P5)

\section{Discussion and Conclusion}

The present study was designed to investigate the experiences of English Language teachers at the tertiary level in the Northern Cyprus context during the online education process resulted from the Covid-19 pandemic period. More specifically, it aimed to explore and explain the perceptions and attitudes of the teachers and the opportunities or challenges they had during this period in terms of (1) work-life balance, (2) professional development, (3) academic activities and research, (4) communication and collaboration among colleagues, (5) relationship with or support from the administration, and (6) online teaching or the use of online tools.

The results of the analysis process showed that although teachers have suffered from certain social, psychological, financial and teaching-related challenges brought by the online education period, they managed to adapt to this new normal thanks to the collaboration with colleagues and make the most of the online teaching and learning process. Regarding the work-life balance, it was revealed that the participants, especially parent-teachers, are struggling to deal with the imbalance in their lives nowadays due to the blurred lines between work and family life. Since working from home did not turn out as the teachers imagined it to be, especially after the schools were closed due to the pandemic and the children started to stay home during the day, they had to face too many responsibilities at the same, which led to fatigue, depression, and even burnout in some teachers. Although these findings are contrary to that of Vyas and Butakhieo (2021), who described working from home as advantageous in terms of reduced commuting time, avoiding office politics, using less office space, increased motivation, job satisfaction, and better 
productivity, they are in line with those of studies that mentioned the tremendous load on the shoulders of teachers in this period (Sokal et al., 2020b; Vu et al., 2020; Vyas \& Butakhieo, 2021).

In terms of online teaching and the use of online tools, the participants revealed that they were dealing with too many duties not only at home in their private lives, but also as a teacher with all those online tools presented to them in this period (Şener et al., 2020). Although the teachers accept that integrating these tools into teaching and doing online teaching facilitated "positive acquisitions in technology use, awareness and skill development" (Karakaya et al.2020; Silman-Karanfil \& Can, 2021), they also stated that it took some time, practice, and devotion to adapt to the new situation, which sometimes led to exhaustion (Sokal et al., 2020a). Moreover, in addition to the concerns related to online teaching mentioned in the literature, this study also revealed how much assessment and testing-driven English language teaching has become in this institution during this period. The reason for this was explained by the participants as the need for the EPP to prove itself to several stakeholders including teachers, students, parents, or the higher administration, due to the changing institutional practices and as the need to better understand student needs and quality.

Compared to the existing literature on the experiences of ELT teachers during the online education process in the Covid-19 period, the present study provided more detailed data on collegial relations and the relationship with the school administration. Regarding the collegial relations, communication and collaboration among colleagues during the online education process were highly spoken of by the participants in this study. In contrast to the studies that were conducted in different contexts and found that teachers needed more support from other teachers (Dolonen et al. as cited in Damia et al., 2021), and they suffered from remote communication problems with colleagues, which led to slow and extended work (Oyedotun, 2020; Şener et al., 2020), most of the participants in this study stated that collaboration among colleagues reached to a peak in this period for them after going through a limited contact period due to the uncertainty or health concerns at the very beginning. However, the data regarding the relationship with or support from the school administration did not yield the same positive feelings. In line with the results of the study conducted by Dolonen et al. (as cited in Damşa et al., 2021) and Şener et al. (2020), the findings of the present study revealed that the participants couldn't get the support they expected from the school administration either financially or emotionally. Focusing on aspects such as lack of technological tools, economic struggles, and lack of transparency, teachers mentioned how they felt left alone in the middle of a jungle without guidance about where to go, what to do, or what is waiting for them. On the other hand, it is also striking to see that teachers who hold administrative positions can actually look at this situation from a broader perspective by considering the macro-level relations, such as the one between the university and the governmental bodies.

Different from the previous literature, this study also focused on if/how teachers dealt with their professional development or academic research activities during this period. About the first one, different opinions and experiences were revealed by the participants. While the in-service teacher trainer reported her frustration due to the teacher resistance towards the professional development activities, most of the participants focused on the perks of online education process in terms of the opportunities in teacher development such as improving soft skills such as showing empathy, learning new teaching or testing skills in online education, and attending online conferences or certificate programs without leaving their seats. This finding was unexpected, and it suggests that professional development has become more self-paced than ever during the online education process. Just like professional development, experiences related to academic activities and research varied among participants. While some participants reported that it was challenging to continue their academic studies due to lack of motivation, heavy teaching workload, and limited opportunities to collect data, others stated that thanks to the online education period, new research areas emerged, and following a graduate program became easier with no need for commuting.

Overall, the results of this study indicate that English language teachers have suffered from certain financial, psychological, and teaching-related problems during online education, but they have adapted to balancing the imbalance in their lives with the lessons learned from mistakes or misfortunes. Although they 
burnt their fingers during these mistakes, they managed to make wonders afterward with those fingers, which helped them gain new skills.

The findings of the present study should be considered in light of some limitations. First of all, since the sample size is limited to seven teachers, the results cannot be generalized to all the teachers working at the same institution or to other contexts. Moreover, although the voices of the working mothers in relation to teaching during the online education period could be heard throughout the present study, working dads were invisible as the ones contacted could not attend the study due to the teaching workload and limited time spared for the data collection process. Considering these, future investigations that employ more participants, including working fathers, might yield more diverse results. Furthermore, to widen the scope of the study, English language teacher educators' experiences during the online education period due to the Covid-19 pandemic can also be investigated. Lastly, this study or an extensive version of it can be conducted in other contexts to see the bigger picture in terms of the experiences of ELT teachers trying to teach English online under the conditions of a pandemic period.

Despite the limitations mentioned above, the findings reported here shed new light on the experiences of English language teachers in the online education process and they have provided significant insights for practice as listed below:

1. Institutions can boost their teachers' well-being holding regular share \& care meetings, where they listen to teachers' needs, expectations, and concerns.

2. The teachers should be provided with the necessary equipment to be able to teach from home or a financial support to afford their expenses in the online education process.

3. The institutions should support and motivate the teachers who are pursuing their academic careers and certain incentives, such as workload reduction, should be offered to such teachers.

4. The institutions planning to continue their online education and practices should plan in advance in order to decrease uncertainty for both teachers and the students. If necessary, guidance and trainings should be offered to both parties.

5. Collaboration among colleagues should be encouraged and enhanced for the well-being of the teachers

\section{References}

Bashir, M., Afzal, M. T., \& Azeem, M. (2008). Reliability and validity of qualitative and operational research paradigm. Pakistan journal of statistics and operation research, 4(1), 35-45.

Beach, R., Enciso, P., Harste, J., Jenkins, C., Raina, S. A., Rogers, R., \& Yenika-Agbaw, V. (Eds.). (2009). Exploring the "critical" in critical content analysis of children's literature. In 58th yearbook of the National Reading Conference (pp. 129-143). Oak Creek, WI: National Reading Conference. https://old.coe.arizona.edu/sites/coe/files/critical_content_analysis-nrc.pdf

Black, M. (1954). Metaphor. Proceedings of the Aristotelian Society, 55, 273-294.

Bozkurt, A. \& Sharma, R. C . (2020). Emergency remote teaching in a time of global crisis due to Coronavirus pandemic. Asian Journal of Distance Education. 15(1), i-vi. https://doi.org/10.5281/zenodo.3778083

Cohen, L., Manion, L., \& Morrison, K. (2007). Research methods in education. London: Routledge.

Crawford, J., Butler-Henderson, K., Rudolph, J., \& Glowatz, M. (2020). COVID-19: 20 countries' higher education intra-period digital pedagogy responses. Journal of Applied Teaching and Learning (JALT), 3(1), 1-20, https://doi.org/10.37074/jalt.2020.3.1.7 
Creswell, J. W. (2007). Qualitative inquiry and research design: Choosing among five approaches. Sage Publications.

Creswell, J. W., \& Miller, D. L. (2010). Determining validity in qualitative inquiry, theory into practice. Theory into Practice, 39(3), 37-41.

Damşa, C., Langford, M., Uehara, D., \& Schere, R. (2021). Teachers' agency and online education in times of crisis. Computers in Human Behavior. 121, 106793. https://doi.org/10.1016/j.chb.2021.106793

Dörnyei, Z. (2007). Research methods in applied linguistics. New York, NY: Oxford University Press

Hamilton, E. R. (2016). Picture This: Multimodal representations of prospective teachers' metaphors about teachers and teaching. Teaching and Teacher Education, 55, 33-44. https://doi.org/10.1016/j.tate.2015.12.007

Harrison, H., Birks, M., Franklin, R., \& Mills, J. (2017). Case study research: Foundations and methodological orientations. In Forum Qualitative Sozialforschung/Forum: Qualitative Social Research (Vol. 18, No. 1).

Hermann, M. A., Gorlewski, J., Brookover, D., Walsh, R., Kozachuk, L., Deitz, M., \& Ciminelli, E. (2020). Policy, practice, and parenthood: a study of teacher mothers. Educational Studies, 1-19.

Hodges, C., Moore, S., Lockee, B., Trust, T., Bond, A. (2020, March 27). The difference between emergency remote teaching and online learning. Educause. https://er.educause.edu/articles/2020/3/the-difference-between-emergency-remote-teaching-andonline-learning

Karakaya, F., Adıgüzel, M., Üçüncü, G., Çimen, O., \& Yilmaz, M. (2020). Teachers' views towards the effects of Covid-19 pandemic in the education process in Turkey. Participatory Educational Research, 8(2), 17-30. https://doi.org/10.17275/per.21.27.8.2

Kraft, M. A., Simon, N. S., \& Lyon, M. A. (2021). Sustaining a sense of success: The protective role of teacher working conditions during the COVID-19 pandemic. Journal of Research on Educational Effectiveness, 14(4), 727-769.

Loveless, D. J., Griffith, B., Bérci, M. E., Ortlieb, E., \& Sullivan, P. M. (Ed.). (2014). Academic Knowledge Construction and Multimodal Curriculum Development: IGI Global. https://doi.org/10.4018/978-14666-4797-8

Marín, R., \& Roldan, J. (2010). Photo essays and photographs in visual arts-based educational research. International Journal of Education Through Art, 6(1),7-23. http://doi.org/10.1386/eta.6.1.7_1.

NYU Langone Health. (2020). Wearing three hats: Balancing life as a parent, teacher \& employee during COVID-19. NYU Langone Health. https://nyulangone.org/news/wearing-three-hats-balancing-lifeparent-teacher-employee-during-covid-19

Oyedotun, T. D. (2020). Sudden change of pedagogy in education driven by COVID-19: Perspectives and evaluation from a developing country. Research in Globalization, 2, 100029. https://doi.org/10.1016/j.resglo.2020.100029

Pain, H. (2012). A literature review to evaluate the choice and use of visual methods. International Journal of Qualitative Methods, 11(4), 303-319. https://doi.org/10.1177/160940691201100401

Silman-Karanfil, L., \& Can, İ. (Eds.). (2021, March). Alice in Wonderland or Hamster on a Wheel: Metaphorical Conceptualizations of Emergency Remote Teaching. Paper presented at 8th International Congress on Curriculum and Instruction Curriculum Studies in Life Long Learning.

Strauss, A., \& Corbin, J. (1998). Basics of qualitative research techniques. Thousand oaks, CA: Sage publications. 
Sokal, L., Trudel, L. E., \& Babb, J. (2020). Canadian teachers' attitudes toward change, efficacy, and burnout during the COVID-19 pandemic. International Journal of Educational Research Open, 1, 100016. https://doi.org/10.1016/j.ijedro.2020.100016

Sokal, L., Trudel, L. E., \& Babb, J. (2021). I've had it! Factors associated with burnout and low organizational commitment in Canadian teachers during the second wave of the COVID-19 pandemic. International Journal of Educational Research Open, 2, 100023. https://doi.org/10.1016/j.ijedro.2020.100023

Şener, B., Sağlam-Ertem, İ., \& Meç, A. (2020). Online teaching experiences of ELT instructors. Journal of Educational Technology and Online Learning, 3(3), 340-362. https://doi.org/10.31681/jetol.770418

Taylor, C. (2020, October 4). How to do a critical discourse analysis. Wikihow. https://www.wikihow.com/Do-a-Critical-Discourse-Analysis

Vu, C. T., Hoang, A. D., Than, V. Q., Nguyen, M. T., Dinh, V. H., Le, Q. A. T., Le, T. T., Pham, H. H., \& Nguyen, Y. C. (2020). Dataset of Vietnamese teachers' perspectives and perceived support during the COVID-19 pandemic. Data in brief, 31(10), 105788. https://doi.org/105788. 10.1016/j.dib.2020.105788

Vyas, L., \& Butakhieo, N. (2020). The impact of working from home during COVID-19 on work and life domains: an exploratory study on Hong Kong. Policy Design and Practice, 4(1), 1-18. https://doi.org/10.1080/25741292.2020.1863560

Weber, R. P. (1990). Basic content analysis. Thousand Oaks, CA: SAGE Publications 